\title{
Szabo 2-stent technique for coronary bifurcation lesions: procedural and short- term outcomes
}

\author{
Hongbo Yang, Juying Qian, Zheyong Huang ${ }^{*}$ and Junbo Ge ${ }^{*}$ (D)
}

\begin{abstract}
Background: Provisional 1-stent technique is currently regarded as the default approach for the majority of bifurcation lesions. Nonetheless, 2-stent techniques may be required for complex bifurcations with high compromise risk or fatal consequences of side branch (SB) occlusion. Limitations exist in current approaches, as stents gap, multiple metal layers and stent malapposition caused by imprecise placement with fluoroscopic guide and intrinsic technical defects. This study was designed to investigate the effectiveness of the novel Szabo 2-stent technique for coronary bifurcation lesions.
\end{abstract}

Methods: In the Szabo 2-stent technique, one stent is precisely implanted at the SB ostium with Szabo technique resulting in a single strut protruding into the main vessel (MV). After MV rewiring and SB guidewire withdrawal, another stent is implanted in MV followed by proximal optimization technique, SB rewiring, and final kissing inflation (FKI).

Results: The technique tested successfully in silicone tubes $(n=9)$ with: procedure duration, $31.2 \pm 6.8 \mathrm{~min}$; MV and SB rewiring time, $26.8 \pm 11.2 \mathrm{~s}$ and $33.3 \pm 15 \mathrm{~s}$; easy FKl; and $2.3 \pm 0.5$ balloons/procedure. Bifurcation lesions $(n=22)$ were treated with angiographic success in $\mathrm{MV}$ and $\mathrm{SB}$, respectively: increased minimal lumen diameter $(0.63 \pm 0.32$ $\mathrm{mm}$ to $3.20 \pm 0.35 \mathrm{~mm} ; 0.49 \pm 0.37 \mathrm{~mm}$ to $2.67 \pm 0.25 \mathrm{~mm}$ ); low residual stenosis (12.4 $\pm 2.4 \%$; $12.4 \pm 2.3 \%$ ); and intravascular ultrasound confirmed $(n=19)$ full coverage; minimal overlap and malapposition; minimal lumen area $\left(2.4 \pm 1.2 \mathrm{~mm}^{2} ; 2.1 \pm 1.0 \mathrm{~mm}^{2}\right)$; plaque burden $(78.1 \pm 11.3 \% ; 71.6 \pm 15.5 \%) ;$ and minimal stent area $\left(9.1 \pm 1.6 \mathrm{~mm}^{2}\right.$; $6.1 \pm 1.3 \mathrm{~mm}^{2}$ ). Periprocedural cardiac troponin increased in 1 asymptomatic patient without electrocardiographic change. There was no target lesion failure (cardiac death, myocardial infarction, target lesion revascularization) at 6month follow-up.

Conclusions: The Szabo 2-stent technique for bifurcation lesions provided acceptable safety and efficacy at shortterm follow-up.

Keywords: Coronary bifurcation, Percutaneous coronary intervention, 2-stent technique, Szabo technique

\footnotetext{
* Correspondence: zheyonghuang@126.com; jbge@zs-hospital.sh.cn

Department of Cardiology, Zhongshan Hospital, Fudan University, Shanghai Institute of Cardiovascular Diseases, Xietu Road No. 1609, Shanghai 200032, People's Republic of China
}

C C The Author(s). 2020 Open Access This article is licensed under a Creative Commons Attribution 4.0 International License, which permits use, sharing, adaptation, distribution and reproduction in any medium or format, as long as you give appropriate credit to the original author(s) and the source, provide a link to the Creative Commons licence, and indicate if changes were made. The images or other third party material in this article are included in the article's Creative Commons licence, unless indicated otherwise in a credit line to the material. If material is not included in the article's Creative Commons licence and your intended use is not permitted by statutory regulation or exceeds the permitted use, you will need to obtain permission directly from the copyright holder. To view a copy of this licence, visit http://creativecommons.org/licenses/by/4.0/ The Creative Commons Public Domain Dedication waiver (http://creativecommons.org/publicdomain/zero/1.0/) applies to the data made available in this article, unless otherwise stated in a credit line to the data. 


\section{Introduction}

Percutaneous coronary intervention (PCI) of complex bifurcation lesions remains a challenge for interventional cardiologists because of its lower success rate and poor outcomes [1,2]. Based on studies documenting superiority of provisional 1-stent approach to systemic 2-stent techniques, provisional stenting of the side branch (SB) after main vessel (MV) stenting is currently regarded as the default approach for the majority of bifurcation lesions [3-8]. Nonetheless, fatal consequences can occur from large branch compromise when the provisional 1stent strategy is unconditionally performed for bifurcation lesions $[8,9]$. Therefore, 2-stent techniques should be considered in case of large SB caliber with severe ostial lesion, diffuse lesion, difficult access, or high risk of compromise $[9,10]$.

A wide variety of 2 -stent techniques have been described, including culotte, crush, $\mathrm{T}$ stenting and their derivative techniques $[1,2]$. Unfortunately, no current technique can avoid the problems of erroneous stent placement, either too far or too proximal with struts protrusion into MV. The ideal technique should provide full coverage with no metal gaps and minimal overlap between the MV and SB stents [11, 12]. Imaging and clinical outcomes have been improved with the development of 2-stent techniques, such as mini-crush, $\mathrm{T}$ and protrusion stenting, among others [12-15]. However, technical evolution approached but did not meet the ideal criteria of "full coverage, minimal overlap, and minimal distortion."

Szabo technique, using a second angioplasty guidewire to anchor the stent at the ostium by passing the proximal end of the anchoring guidewire through the last cell of the stent, has been used successfully in precise positioning of the ostial coronary artery [16-19]. Theoretically, the Szabo technique could be used as a 2-stent technique for bifurcation lesions to facilitate the accurate placement of the SB stent. Here, we describe initial bench testing and clinical application of Szabo 2-stent technique for bifurcation lesions.

\section{Materials and methods}

Bench testing

The Szabo 2-stent technique was evaluated first in vitro. Tests were performed in silicone tubes (Fig. 4) with different bifurcation angles. Guiding catheter was positioned and guidewires were advanced into both branches.

\section{Preparation of side branch stent}

Preparation of SB stent is shown in Fig. 1. Firstly, the last cell of the stent was lifted up by 4 atm inflation of the stent balloon, with most of the stent remaining inside the protective sheath and only the last cell free (Fig. 1a). When the proximal end of the stent was seen to have flared, the balloon was immediately deflated leaving the last strut free (Fig. 1b). Then, the proximal

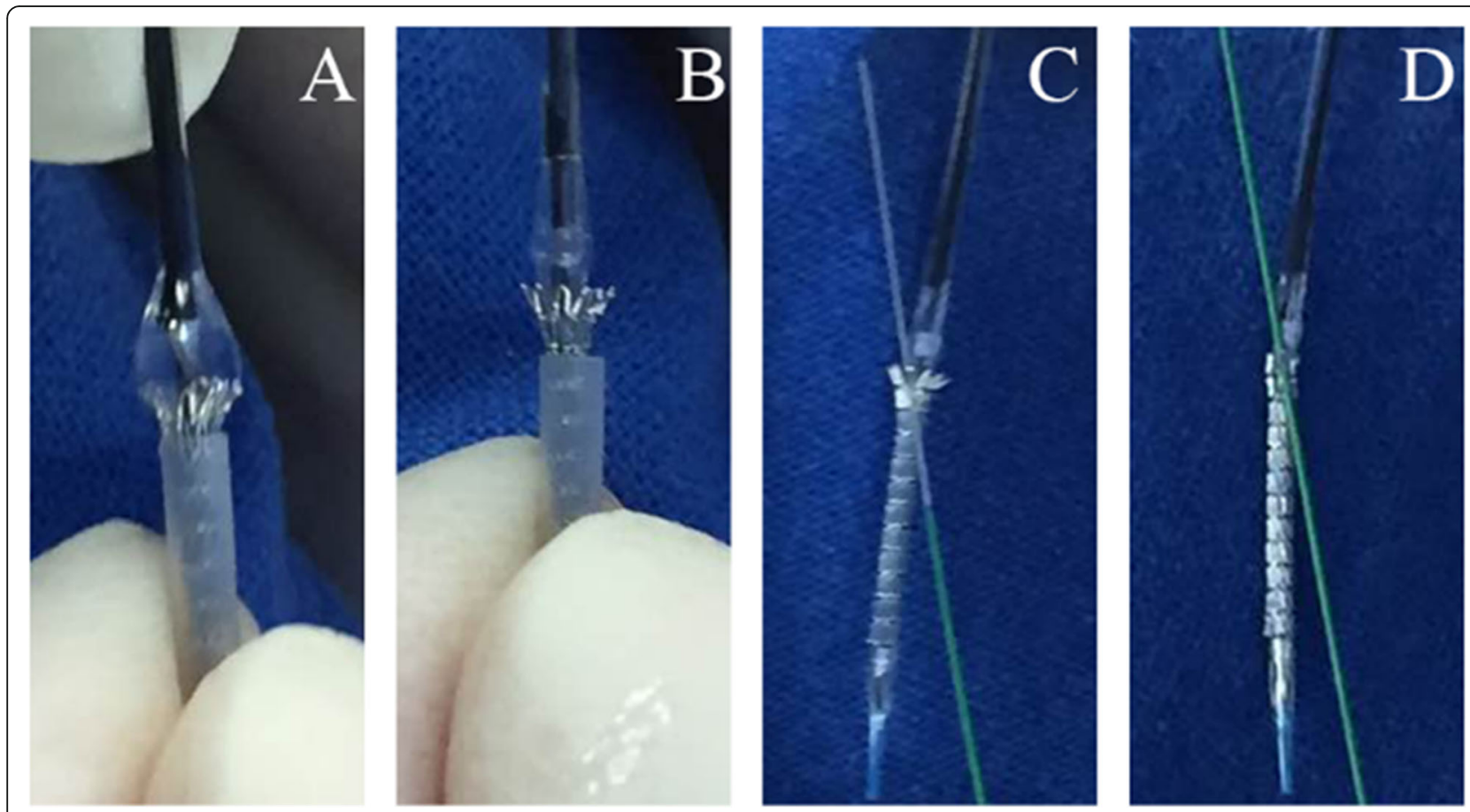

Fig. 1 Stent preparation. a Inflation with 4 atm. b Deflation. c Anchoring guidewire threading. d Manually crimped flared end of the stent back into place 
end of the anchoring guidewire in MV was carefully threaded through the last strut of the stent to avoid balloon injury (Fig. 1c). Finally, the flared end of the stent was manually crimped back into place (Fig. 1d).

\section{Szabo 2-stent procedure}

With lesion and stent preparation, the SB stent moved freely over both guidewires and was advanced into the SB until further forward movement was blocked by the anchoring guidewire in MV. Coronary angiography confirmed the position of stent at the bifurcation without guidewire wrap. Then final placement was identified by slight bending of the anchoring guidewire at the ostial junction (Fig. 2a) (Online Video 1). At this time, the stent was initially deployed at $8 \mathrm{~atm}$ (Fig. 2b) (Online Video 2). The tail guidewire was then easily retracted, and a high-pressure inflation (14 atm) was performed.

Next, the guidewire was rewired into distal MV free from strut (Fig. 2c) or another guidewire was advanced into distal MV before SB stent inflation (Online Video 3). SB stent was inflated with stent balloon for optimization (Fig. 2d).

SB stenting with Szabo technique ensured that the stent struts covered lesion completely and was exactly positioned at the ostial SB with only one strut protruding into the MV (Fig. 2e). The MV stent was positioned and deployed (Fig. 2f), followed by proximal optimization technique with a short noncompliant balloon (Fig. $2 \mathrm{~g}$ ).

Then, SB rewiring (Fig. 2h, Online Video 4) and final kissing inflation (FKI) (Fig. 2i, Online Video 5) was performed to obtain best results (Fig. 2j).

\section{Patient population}

Between November 2018 and May 2019, patients with angina pectoris, attributing to bifurcation lesions without any significant stenosis in other coronary arteries, were selected to undergo treatment using the Szabo 2-stent technique. The bifurcation lesions had $>50 \%$ diameter stenosis in both the MV and the ostial SB, and SB stenosis extending for $>5 \mathrm{~mm}$. Of them, severe consequences can occur from the large branch compromise with difficult access. The study was approved by the institutional ethics committee and conformed with the principles of the Declaration of Helsinki. Informed consent for coronary angiography and stent implantation was obtained from all the patients.

\section{Study procedures and medications}

With oral dual antiplatelet drug pretreatment, intravenous bolus of heparin $(100 / \mathrm{kg})$ was administered to all patients before angioplasty. Angiograms in multiple

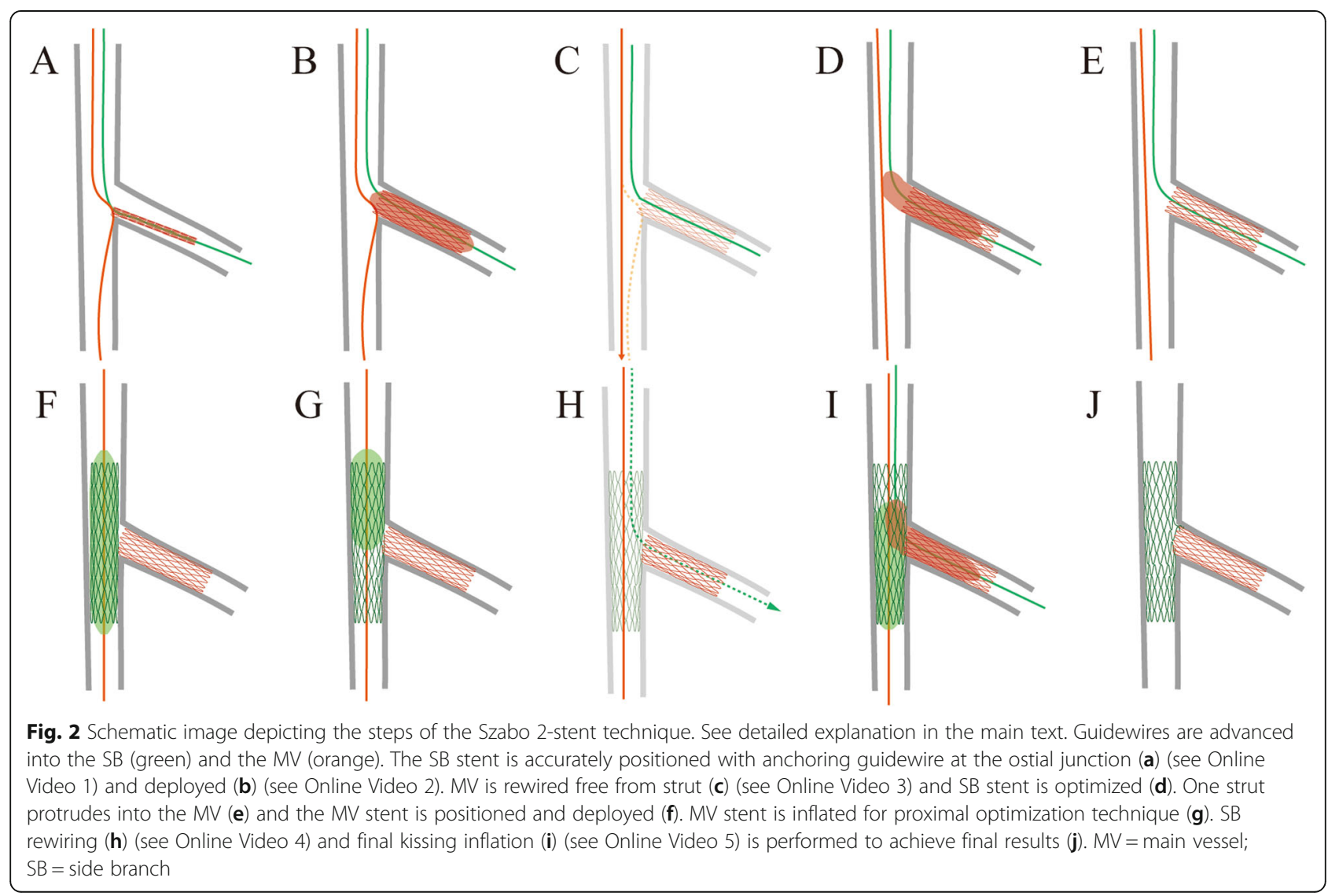


views were obtained using the transradial approach, and 2-stent strategies were planned.

Guiding catheter was engaged and guidewires were advanced into the diseased arteries. Intravascular ultrasound (IVUS) (OptiCross, Boston Scientific, USA) was performed to confirm the plaque distribution and characteristics. Step-by-step Szabo 2-stent procedure in a patient is illustrated in Fig. 3.

Lesions assessment and preparation were at operator's discretion. Baseline angiogram was presented in Fig. 3a. With preparation of lesions and stent, the SB stent was accurately positioned (Fig. 3b) (Online Video 6) and deployed (Fig. 3c) at the ostial junction with Szabo technique.

With MV rewiring free from strut (Fig. 3d) (Online Video 7), SB stent was optimized with stent balloon inflation (Fig. 3e). Coronary angiography and IVUS of both branches (Online Videos 8 and 9) were performed to confirm struts coverage and protrusion.

Next, MV stenting (Fig. 3f) followed by proximal optimization technique (Fig. 3g), and SB rewiring (Fig. 3h) (Online Video 10). Finally, FKI (Fig. 3i) (Online Video 11) was performed to achieve the best results (Fig. 3j). IVUS of both branches (Online Videos 12 and 13) was performed to confirm struts gap and overlap.

\section{Quantitative analysis}

Quantitative analysis was done by an experienced cardiologist. Quantitative angiography analysis was performed by standard techniques with automated edge-detection algorithms (CASS-5.2, Pie Medical, Maastricht, the Netherlands). IVUS imaging was performed after intracoronary administration of $0.2 \mathrm{mg}$ nitroglycerin, using motorized transducer pullback $(0.5 \mathrm{~mm} / \mathrm{s})$ and a commercial scanner (OptiCross, Boston Scientific, MA, USA). The IVUS data were stored on DVD, and quantitative IVUS analysis (EchoPlaque 3.0, Indec Systems, MountainView, CA, USA) was performed off-line by a single experienced investigator.

\section{Follow-up and outcomes}

Clinical follow-up was performed by office visit or telephone contact at 1,3 , and 6 months. The endpoint was target lesion failure, the composite of cardiac death, myocardial infarction and target lesion revascularization at 6-month follow-up.

\section{Results}

\section{Bench testing}

Bench testing was successfully performed according to the protocol in all 9 procedures with 2 stents per case. Procedure duration was $31.2 \pm 6.8(22-41) \mathrm{min}$. After SB stenting, MV rewiring time was $26.8 \pm 11.2(15-50)$ s. Another guidewire was needed to complete the $\mathrm{SB}$ rewiring in 1 case, thus average SB rewiring time was $33.3 \pm 15.4$ (18-70) s. Because of the discrepancy between proximal and distal tube diameters, the initially chosen noncompliant balloons for MV inflation were not suitable for FKI in 3 cases, and on average, $2.3 \pm 0.5$ balloons were used per procedure. Representative results of 3 cases are shown in Fig. 4.
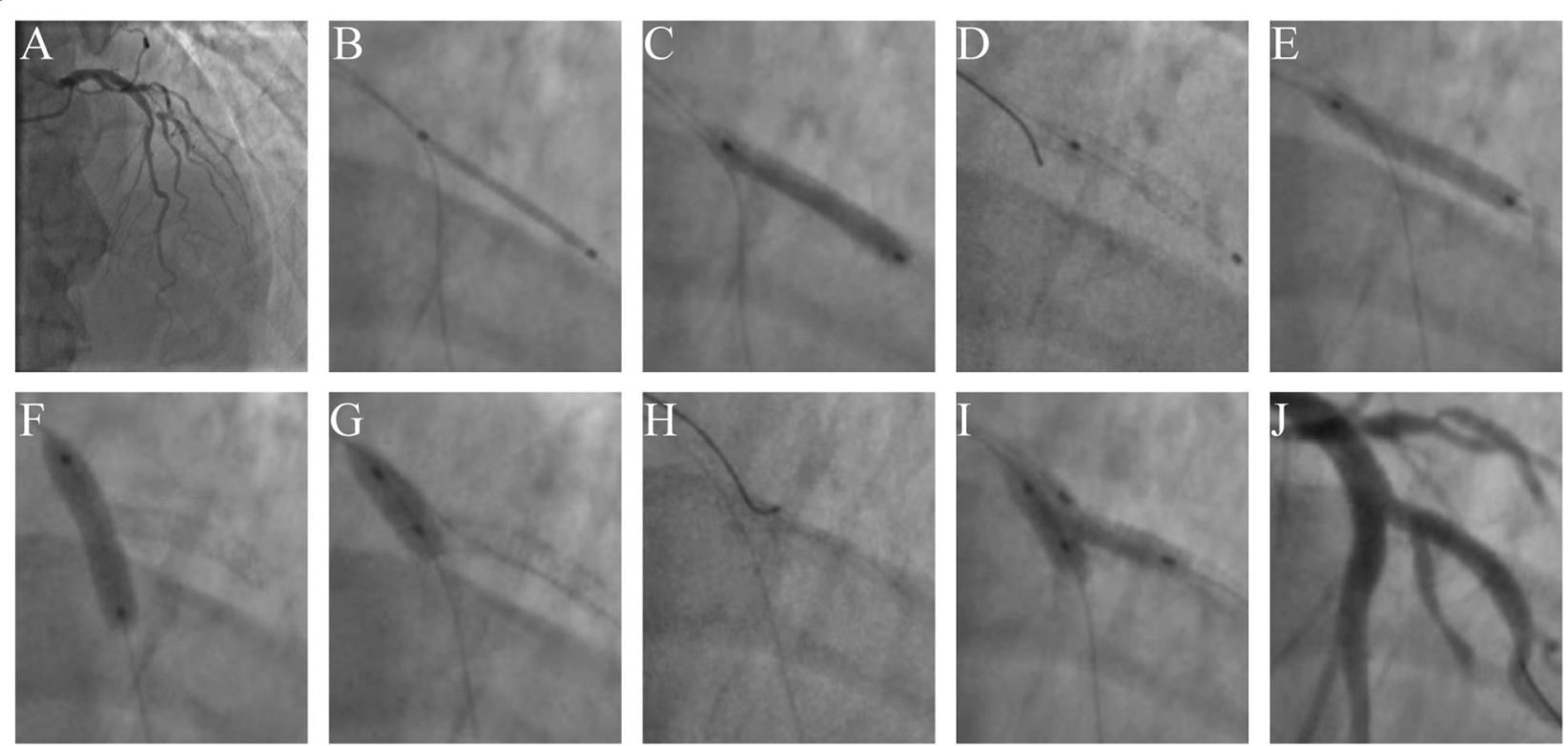

Fig. 3 Step-by-step Szabo 2-stent technique application in a patient. Baseline coronary angiogram was presented in (a). Diagonal stent is precisely positioned (b) (see Online Video 6) and deployed (c). LAD rewiring free from strut (d) (see Online Video 7) and optimizing diagonal stent (e) results in one strut protrusion into LAD (see Online Videos 8 and 9). LAD stenting (f) and optimization (g) followed by diagonal branch rewiring (h) (see Online Video 10) and final kissing inflation (i) (see Online Video 11). Final result (j) is assessed by coronary angiography (j) and intravascular ultrasound (see Online Videos 12 and 13) to confirm the struts gap and overlap. LAD= left anterior descending artery 

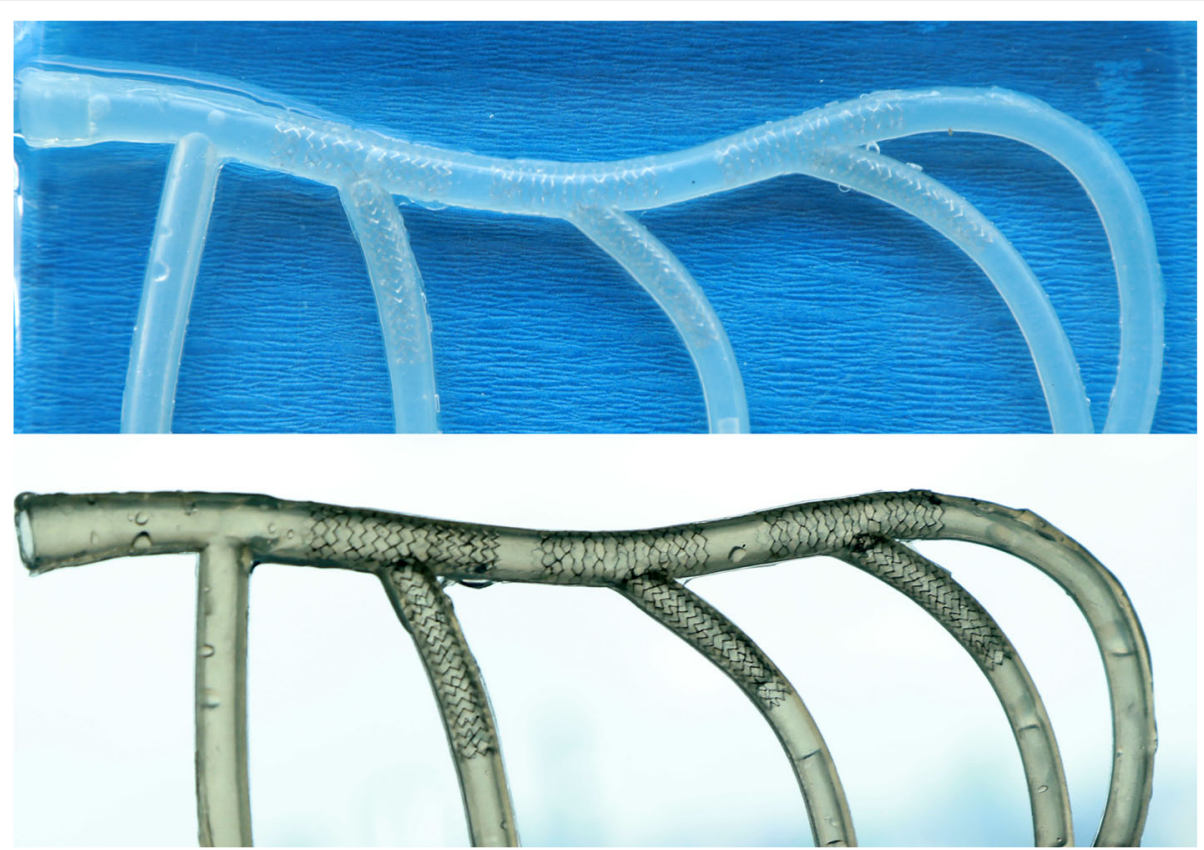

Fig. 4 Results of bench testing. Three representative examples from the in vitro procedures show no stent gap with minimal overlap and malapposition of the stents

\section{Baseline characteristics}

Between November 2018 and May 2019, Szabo 2-stent technique was successfully performed in 22 consecutive patients with Medina 1,1,1 bifurcation lesions according to the standardized protocol. The baseline characteristics are summarized in Table 1 . Of 22 patients, 16 were male; mean age was $69 \pm 11$ years; and there was a high proportion of hypertension (81.8\%). The indication for PCI was acute coronary syndrome in 10 cases and stable angina in 12 cases. Target bifurcation was located at left main stem in 12 cases and at left anterior descending artery and the diagonal branch in 10 cases. Six cases had mild calcification and none had severe tortuosity.

\section{Quantitative coronary angiography analysis}

Lesion and procedural characteristics are presented in Table 2. Treated branches were large, and diameter of all implanted stents was $\geq 2.75 \mathrm{~mm}$. Of the 22 stents successfully implanted with Szabo technique, 7 were Promus or Synergy (Boston Scientific, USA), and 5 Xience (Abbott Vascular, USA), 4 Resolute (Medtronic, USA), 3 Firehawk (MicroPort, China) and 3 Excrossal (JW Medical Systems, China). Quantitative coronary angiography analysis showed that mean reference vessel diameters and minimal lumen diameters were $3.29 \pm 0.20 \mathrm{~mm}$ and $0.63 \pm 0.32 \mathrm{~mm}$ in the $\mathrm{MV}$, and $2.69 \pm 0.31 \mathrm{~mm}$ and $0.49 \pm 0.37 \mathrm{~mm}$ in the $\mathrm{SB}$, respectively. Mean lesion length of the MV and SB was $24.1 \pm 12.8 \mathrm{~mm}$ and $22.0 \pm$ $16.7 \mathrm{~mm}$, respectively. Mean stent diameter and length were $3.5 \pm 0.3 \mathrm{~mm}$ and $30.9 \pm 16.9 \mathrm{~mm}$ in the $\mathrm{MV}$, and
$3.0 \pm 0.3 \mathrm{~mm}$ and $27.3 \pm 18.1 \mathrm{~mm}$ in the SB, respectively. Maximal inflation pressure was $18.0 \pm 4.0 \mathrm{~atm}$ and $17.3 \pm 3.2 \mathrm{~atm}$ in the MV and SB stents, respectively. FKI was performed in all patients with mean inflation pressure of $11.6 \pm 0.8 \mathrm{~atm}$. Angiographic success was

Table 1 Clinical Characteristics of the patients $(n=22)$

\begin{tabular}{ll}
\hline Age, $y$ & $69.4 \pm 11.1$ \\
\hline Male & $16(72.3)$ \\
Hypertension & $18(81.8)$ \\
Diabetes & $2(9.1)$ \\
Hyperlipidemia & $2(9.1)$ \\
Smoking & $6(27.3)$ \\
Clinical manifestation & \\
$\quad$ Stable angina & $12(54.5)$ \\
$\quad$ Acute coronary syndrome & $10(45.5)$ \\
Prior PCl & $4(18.2)$ \\
eGFR, mL/min/1.73m² & $81.2 \pm 18.6$ \\
LVEF, \% & $63.1 \pm 4.9$ \\
Bifurcation & \\
$\quad$ LAD/LCX & $12(54.5)$ \\
LAD/Dg & $10(45.5)$ \\
Angle $>70^{\circ}$ & $10(45.5)$ \\
Calcification & $6(27.3)$ \\
\hline Da are presen
\end{tabular}

Data are presented as mean $\pm \mathrm{SD}$ or $\mathrm{n}(\%)$. Dg diagonal branch, eGFR estimated glomerular filtration rate, $L A D$ left anterior descending coronary artery, $L C X$ left circumflex coronary artery, $L V E F$ left ventricular ejection fraction, $P C l$ percutaneous coronary intervention 
Table 2 Quantitative coronary angiographic analysis

\begin{tabular}{|c|c|c|}
\hline & Main vessel $(n=22)$ & Side branch $(n=22)$ \\
\hline \multicolumn{3}{|l|}{ Pre-procedure } \\
\hline Reference diameter, mm & $3.29 \pm 0.20$ & $2.69 \pm 0.31$ \\
\hline Minimal lumen diameter, mm & $0.63 \pm 0.32$ & $0.49 \pm 0.37$ \\
\hline Percent diameter stenosis, \% & $81.8 \pm 11.2$ & $82.3 \pm 12.4$ \\
\hline Lesion length, mm & $24.1 \pm 12.8$ & $22.0 \pm 16.7$ \\
\hline \multicolumn{3}{|l|}{ Procedure } \\
\hline Total stent length, mm & $30.9 \pm 16.9$ & $27.3 \pm 18.1$ \\
\hline Maximal stent diameter, mm & $3.5 \pm 0.3$ & $3.0 \pm 0.3$ \\
\hline Number of stents & $1.3 \pm 0.5$ & $1.4 \pm 0.7$ \\
\hline Maximal balloon diameter, mm & $3.6 \pm 0.4$ & $3.0 \pm 0.3$ \\
\hline Maximal inflation pressure, atm & $18.0 \pm 4.0$ & $17.3 \pm 3.2$ \\
\hline Final kissing inflation pressure, atm & $11.6 \pm 0.8$ & \\
\hline \multicolumn{3}{|l|}{ Post-procedure } \\
\hline Minimal lumen diameter, mm & $3.20 \pm 0.35$ & $2.67 \pm 0.25$ \\
\hline Percent diameter stenosis, \% & $12.4 \pm 2.4$ & $12.4 \pm 2.3$ \\
\hline Acute gain, mm & $2.57 \pm 0.45$ & $2.18 \pm 0.44$ \\
\hline
\end{tabular}

Data are presented as mean \pm SD. atm atmosphere

achieved in all patients with residual stenosis of $12.4 \pm$ $2.4 \%$ and $12.4 \pm 2.3 \%$ in the MV and SB, respectively. Minimal lumen diameters of the MV and SB increased to $3.20 \pm 0.35 \mathrm{~mm}$ and $2.67 \pm 0.25 \mathrm{~mm}$, respectively.

\section{IVUS analysis}

Three patients refused IVUS examination for financial reasons, so that IVUS was performed in other 19 patients to confirm full coverage, minimal strut protrusion and overlap. Representative IVUS images are shown in Online videos. After diagonal branch stenting, full coverage of ostial diagonal branch and 1 strut protrusion into left anterior descending artery were assessed from both branches (Online Videos 8 and 9). With Szabo 2-stent technique procedure, no struts gap, minimal overlap and malapposition was checked (Online Videos 12 and 13). Quantitative IVUS data are shown in Table 3. Minimal lumen area and plaque burden were $2.4 \pm 1.2 \mathrm{~mm}^{2}$ and

Table 3 Quantitative intravascular ultrasound analysis

\begin{tabular}{lll}
\hline & $\begin{array}{l}\text { Main vessel } \\
(n=19)\end{array}$ & $\begin{array}{l}\text { Side branch } \\
(n=19)\end{array}$ \\
\hline $\begin{array}{lll}\text { Pre-procedure } \\
\text { Reference vessel area, } \mathrm{mm}^{2}\end{array}$ & $10.6 \pm 1.8$ & $7.1 \pm 1.3$ \\
$\quad \begin{array}{l}\text { Minimal lumen area, } \mathrm{mm}^{2} \\
\text { Plaque burden, \% }\end{array}$ & $2.4 \pm 1.2$ & $2.1 \pm 1.0$ \\
Post-procedure & $78.1 \pm 11.3$ & $71.6 \pm 15.5$ \\
Minimal stent area, $\mathrm{mm}^{2}$ & $9.1 \pm 1.6$ & $6.1 \pm 1.3$ \\
Acute gain, $\mathrm{mm}^{2}$ & $6.7 \pm 1.8$ & $4.0 \pm 1.7$ \\
\hline
\end{tabular}

Data are presented as mean \pm SD
$78.1 \pm 11.3 \%$ in the MV, and $2.1 \pm 1.0 \mathrm{~mm}^{2}$ and $71.6 \pm$ $15.5 \%$ in the SB, respectively. With successful procedure, minimal stent areas of the $\mathrm{MV}$ and $\mathrm{SB}$ reached up to $9.1 \pm 1.6 \mathrm{~mm}^{2}$ and $6.1 \pm 1.3 \mathrm{~mm}^{2}$.

\section{Follow-up}

Cardiac troponin level increased over 5 times the upper limit of the $99 \%$ confidence interval in only one asymptomatic patient with no electrocardiographic changes. All patients underwent at least 6-month follow-up (range, 6-11 months). During this period, no target lesion failure was noted, including cardiac death, myocardial infarction, or target lesion revascularization. At a routine visit 11 months after the index procedure, coronary angiography and IVUS in one representative patient revealed only mild neointimal proliferation (Fig. 5).

\section{Discussion}

To the best of our knowledge, this is the first study on use of the novel Szabo 2-stent technique for treatment of bifurcation lesions, which appeared feasible with high rate of procedural success and safe up to 6-moth follow-up.

Coronary bifurcation lesions are frequent and account for approximately $15-20 \%$ of total PCIs. Nonetheless, PCI for bifurcation lesions is challenging due to its lower procedural success and poor outcomes. Provisional stenting of the SB is the preferred strategy according to the KISSS principle (Keep it simple, swift and safe) [19]. However, the need for bailout stenting in provisional 1-stent approach increases the risks of delivery failure, 

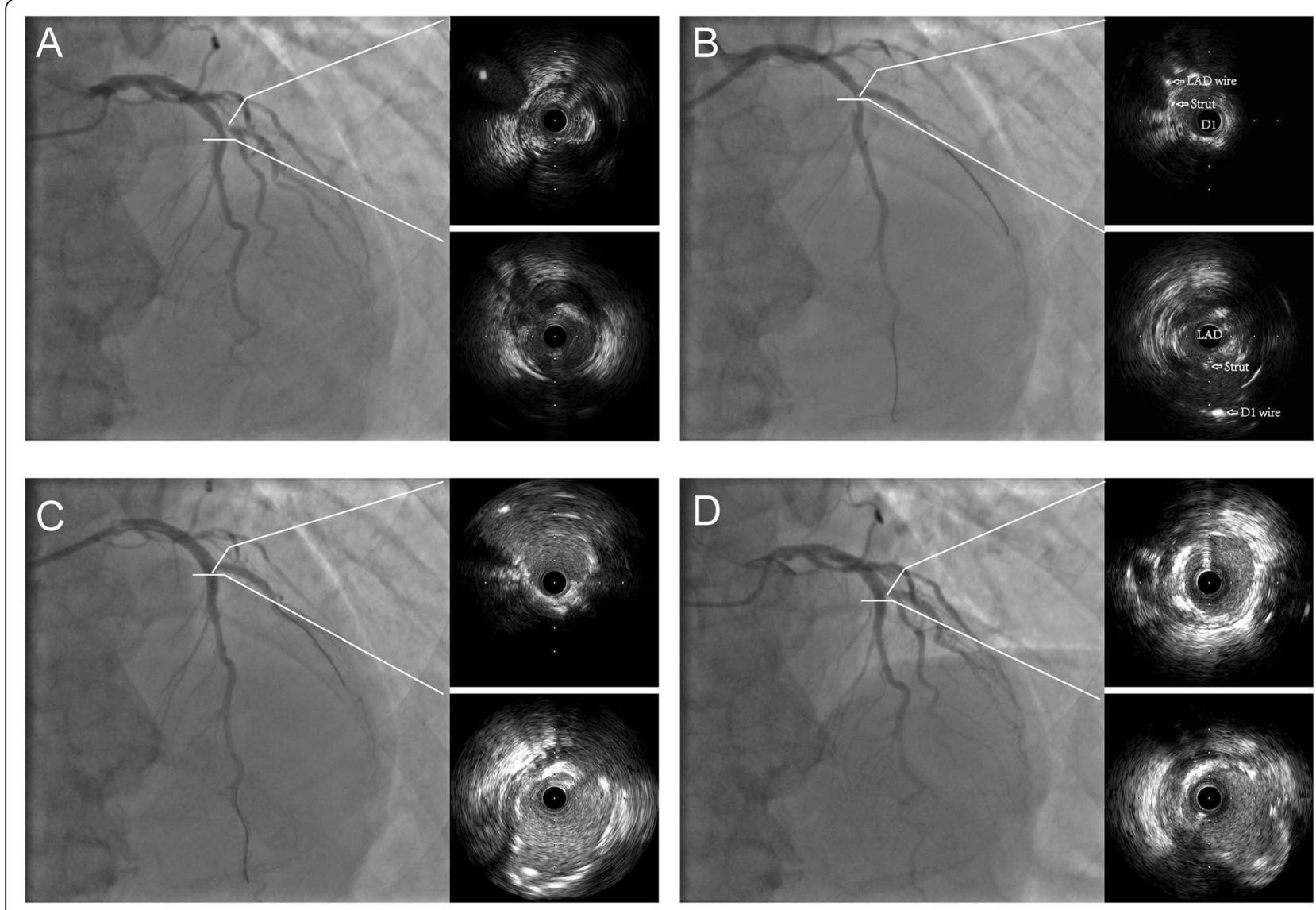

Fig. 5 Representative follow-up results of 1 patient. a Baseline images with true bifurcation lesion. $\mathbf{b}$ Accurate placement of stent in the first diagnol branch with 1 strut protruding into the left anterior descending artery. c Postprocedure with minimal overlap and malapposition. $\mathbf{d}$ Follow-up results with mild neointimal proliferation

misplacement or under-expansion of the SB stent, and edge dissection, which could increase the rate of occurrence of significant adverse clinical outcomes driven by target vessel failure and stent thrombosis $[6,20]$. Therefore, 2-stent techniques with SB stenting should be considered first in complex bifurcation with difficult access, dissections, high risk of occlusion or need for multiple stents to cover downstream lesions of SB.

Several 2-stent techniques have been developed for bifurcation lesions. $T$ stenting technique was first used with easily applicable and reproducible steps. To decrease restenosis at the ostium of SB stent caused by incomplete coverage of $\mathrm{T}$ stenting technique [21], crush and culotte stenting techniques were developed [22, 23]. New problems then arose, such as overlap, multiple metal layers, stent malapposition and under-expansion of stent strut at the ostial SB, which increased restenosis and stent thrombosis [24]. Mini-crush, mini-culotte, double kissing-crush, and nano-crush techniques evolved to minimize overlap and metal burden and to improve clinical outcomes [1, 2, 13-15]. Nonetheless, a significant risk of geographic miss or excessive overlap is inevitably associated with these techniques, which are guided by fluoroscopic placement of the SB stent.

The Szabo technique was first used to accurately position stents in areas with physical barriers; appropriate mechanical placement is important to avoid excessive forward progression at the ostial lesions, reduce the incidence of angiographic malapposition, and ensure full coverage of ostial lesion and minimal protrusion of struts [16-19]. The Szabo technique was associated with favorable outcomes at 2 years follow-up [25]. Thus, the Szabo technique may facilitate precise placement of SB stents, the Szabo 2-stent technique could be used in bifurcation lesions. Here, we investigated the feasibility and safety of the Szabo 2-stent technique for the treatment of bifurcation lesions. During the procedure, after preparation of lesions and stent, the first stent is implanted exactly at the proximal rim of the SB ostium with Szabo technique, resulting in a single strut protruding into the MV. Bending of the anchoring MV wire may happen in some different scenarios like ectatic distal MV or proximal guidewire wrap. Coronary angiography confirms the SB direction and the position of stent at 
the bifurcation without coronary ectasia or guidewire wrap. Then final placement is identified by slight bending of the anchoring guidewire at the ostial junction to insure exact location. Variety of stent types have been applied in SB ostium with Szabo technique. With MV rewiring and guidewire withdrawal from the $\mathrm{SB}$, the $\mathrm{MV}$ stent is positioned and deployed. After proximal optimization technique and SB rewiring at more distal side holes, the procedure finishes with FKI to guarantee potential strut gap in sharp acute angles.

Szabo 2-stent technique might be theoretically superior to many, if not all, 2-stent techniques. First, misplacement of fluoroscopic guide is overcome with anchoring guidewire. Next, it may be superior to crush and culotte stenting with minimal stent overlap of only 1 strut, and better than $\mathrm{T}$ stenting with complete coverage of SB ostium. Moreover, Szabo 2-stent technique diminishes malapposition and neocarina formation in $\mathrm{T}$ and Protrusion stenting and kissing stenting. Furthermore, easier rewiring and balloon insertion through stent struts could result in higher FKI rate in Szabo 2stent technique, probably because of the need to cross 1 layer of stent strut versus 3 layers in the crush technique. The novel technique overcomes the vessel diameter discrepancy between the SB and MV in culotte stenting. In addition, different kinds of stents could be successfully used with this technique, which avoids the limitation of single string technique in which cell diameter of SB stent must expand up to at least $4 \mathrm{~mm}$ for MV stenting. What's more, it could be used in provisional 2-stent technique for accurate placement of SB stent as reverse Szabo 2-stent technique. The Szabo 2-stent technique causes minimal deformation of stents (minimal strut protrusion, overlap, malapposition) and vessel structures (full coverage, optimal openings at the ostium, bifurcation angulation), rendering it theoretically ideal to accomodate to the native anatomic structure and preserve its physiological characteristics. Although some of the abovementioned technical and physiological advantages remain to be investigated, it can be anticipated that near-intact anatomy and geometry will translate into pathophysiological and clinical benefits.

In fact, the high procedural success rate and good short-term outcomes demonstrated the feasibility and safety of the Szabo 2-stent technique in this study. A multicenter prospective randomized study comparing the Szabo 2-stent technique with other techniques is warranted to confirm and extend into long-term followup the promising results obtained in this single center study.

\section{Study limitations}

The Szabo technique is challenging for some operators. Attention must be paid to complications, such as guidewire entanglement, stent dislodgement and resistance during stent advancement [26, 27]. The operator needs some experience and training to be familiar with this technique, especially be alert to the potential risk of stent displacement from the balloon during stent positioning as stent/balloon integrity may be damaged by the low-pressure inflation. One concern is the risk of comprised blood flow in main branch after SB stenting. A safer method is to advance a new guidewire to the distal MV before withdrawing the anchoring guidewire. If unsuccessful, a small balloon needs to be advanced along the anchoring guidewire to inflate the protruding stent cell, and then the MV stent is deployed across this protruding stent cell, similar to the single string technique [12]. Lack of 3D optical coherence tomography to assess the metallic neocarina and the position of guidewire recrossing through the MV stent into the SB is another limitation. We tested Szabo 2-stent technique in left main or proximal LAD, but not in more distal bifurcations or in more tortuous anatomies or in smaller anatomies with potential higher risk of wrapping up of the 2 wires. 2-stent strategy is rarely used in more distal bifurcations or in smaller anatomies. Avoiding excessive rotation of wires could help perform Szabo 2-stent technique in tortuous lesions, but the risk of stent dislodgement should be kept in mind. This study could not determine whether the Szabo 2-stent technique is better or worse than provisional or other stenting techniques because of its single center design with short-term follow-up, small sample size, and no control group.

\section{Conclusions}

PCI for bifurcation lesions remains challenging with optimal techniques requiring a balance between complete coverage, minimal stent overlap, and malapposition. In this study, treatment of bifurcation lesions with Szabo 2stent technique appeared feasible with acceptable procedural success rate, short-term outcomes, and full coverage and minimal overlap and malapposition by IVUS. A large, randomized controlled study with longterm follow-up is warranted to confirm the findings in this study.

\section{Supplementary information}

Supplementary information accompanies this paper at https://doi.org/10. 1186/s12872-020-01605-y.

Additional file 1: Online Video 1. Positioning side branch stent with anchoring guidewire at the ostial junction.

Additional file 2: Online Video 2. Inflation of side branch stent. Additional file 3: Online Video 3. Advancing another guidewire to distal main vessel before stent inflation is safer than rewiring.

Additional file 4: Online Video 4. Side branch rewiring.

Additional file 5: Online Video 5. Final kissing inflation. 
Additional file 6: Online Video 6. Positioning the diagonal stent with guidewire in the left anterior descending artery.

Additional file 7: Online Video 7. Rewiring the left anterior descending artery.

Additional file 8: Online Video 8. Full coverage of the diagonal ostium by intravascular ultrasound from the diagonal artery.

Additional file 9: Online Video 9. Only 1 strut protrusion into the left anterior descending artery by intravascular ultrasound from the left anterior descending artery.

Additional file 10: Online Video 10. Rewiring in the diagonal artery.

Additional file 11: Online Video 11. Final kissing inflation.

Additional file 12: Online Video 12. No struts gap and minimal overlap by intravascular ultrasound from the diagonal artery.

Additional file 13: Online Video 13. No geographic miss and minimal overlap by intravascular ultrasound from the left anterior descending artery.

\section{Abbreviations}

FKl: Final kissing inflation; IVUS : Intravascular ultrasound; MV: Main vessel; PCl: Percutaneous coronary intervention; SB: Side branch

\section{Acknowledgments}

The authors would like to thank the research staff for their help.

\section{Authors' contributions}

HY drafted the manuscript. ZH did the procedure and statistical analysis. $\mathrm{ZH}$, $J Q$ and JG helped revising the manuscript for important intellectual content. All authors have read, revised and approved the final manuscript.

\section{Funding}

This work was supported by National Natural Science Foundation of China (81801374 Hongbo Yang, 81870269 Zheyong Huang).

\section{Availability of data and materials}

The datasets used and/or analyzed during the current study are available from the corresponding author on reasonable request.

\section{Ethics approval and consent to participate}

All patients signed written informed consent form. Fudan University affiliated Zhongshan Hospital Ethics Committee had approved the work and received all the written informed consent.

\section{Consent for publication}

Not applicable.

\section{Competing interests}

All authors declare no competing financial interests.

Received: 3 May 2020 Accepted: 26 June 2020

Published online: 07 July 2020

\section{References}

1. Lassen JF, Holm NR, Stankovic G, Lefèvre T, Chieffo A, Hildick-Smith D, et al. Percutaneous coronary intervention for coronary bifurcation disease: consensus from the first 10 years of the European bifurcation Club meetings. Eurolntervention. 2014:10:545-60.

2. Sawaya FJ, Lefèvre T, Chevalier B, Garot P, Hovasse T, Morice M-C, et al. Contemporary approach to coronary bifurcation lesion treatment. JACC Cardiovasc Interv. 2016;9:1861-78.

3. Maeng M, Holm NR, Erglis A, Kumsars I, Niemela M, Kervinen K, et al. Longterm results after simple versus complex stenting of coronary artery bifurcation lesions: Nordic bifurcation study 5-year follow-up results. J Am Coll Cardiol. 2013:62:30-4.

4. Colombo A, Bramucci E, Saccà S, Violini R, Lettieri C, Zanini R, et al. Randomized study of the crush technique versus provisional side-branch stenting in true coronary bifurcations: the CACTUS (coronary bifurcations: application of the crushing technique using Sirolimus-eluting stents) study. Circulation. 2009;119:71-8.
5. Ferenc M, Gick M, Kienzle R-P, Bestehorn H-P, Werner K-D, Comberg T, et al. Randomized trial on routine vs. provisional T-stenting in the treatment of de novo coronary bifurcation lesions. Eur Heart J. 2008;29: 2859-67.

6. Song YB, Park TK, Hahn J-Y, Yang JH, Choi J-H, Choi S-H, et al. Optimal strategy for provisional side branch intervention in coronary bifurcation lesions: 3-year outcomes of the SMART-STRATEGY randomized trial. JACC Cardiovasc Interv. 2016;9:517-26.

7. Kim Y-H, Lee J-H, Roh J-H, Ahn J-M, Yoon S-H, Park D-W, et al. Randomized comparisons between different stenting approaches for bifurcation coronary lesions with or without side branch stenosis. JACC Cardiovasc Interv. 2015;8:550-60.

8. Cho S, Kang TS, Kim J-S, Hong S-J, Shin D-H, Ahn C-M, et al. Long-term clinical outcomes and optimal stent strategy in left Main coronary bifurcation stenting. JACC Cardiovasc Interv. 2018;11:1247-58.

9. Burzotta F, Lassen JF, Banning AP, Lefèvre T, Hildick-Smith D, Chieffo A, et al. Percutaneous coronary intervention in left main coronary artery disease: the 13th consensus document from the European bifurcation Club. Eurolntervention. 2018;14:112-20.

10. Dou K, Zhang D, Xu B, Yang Y, Yin D, Qiao S, et al. An angiographic tool for risk prediction of side branch occlusion in coronary bifurcation intervention: the RESOLVE score system (risk prEdiction of side branch OccLusion in coronary bifurcation interVEntion). JACC Cardiovasc Interv. 2015:8:39-46.

11. Colombo A, Ruparelia N. The relentless attempt to perfect the 2-stent technique. JACC Cardiovasc Interv. 2015:8:960-1.

12. Toth G, Pyxaras S, Mortier P, De Vroey F, Di Gioia G, Adjedj J, et al. Single string technique for coronary bifurcation stenting: detailed technical evaluation and feasibility analysis. JACC Cardiovasc Interv. 2015:8:949-59.

13. Galassi AR, Colombo A, Buchbinder M, Grasso C, Tomasello SD, Ussia GP, et al. Long-term outcomes of bifurcation lesions after implantation of drugeluting stents with the "mini-crush technique". Catheter Cardiovasc Interv. 2007;69:976-83.

14. Chen S-L, Zhang J-J, Han Y, Kan J, Chen L, Qiu C, et al. Double kissing crush versus provisional stenting for left Main distal bifurcation lesions: DKCRUSHV randomized trial. J Am Coll Cardiol. 2017;70:2605-17.

15. Rigatelli G, Zuin M, Vassilev D, Dinh H, Giatti S, Carraro M, et al. Culotte versus the novel nano-crush technique for unprotected complex bifurcation left main stenting: difference in procedural time, contrast volume and X-ray exposure and 3-years outcomes. Int I Card Imaging. 2019;35:207-14

16. Kern MJ, Ouellette D, Frianeza T. A new technique to anchor stents for exact placement in ostial stenoses: the stent tail wire or Szabo technique. Catheter Cardiovasc Interv. 2006:68:901-6.

17. Lo H, Kern MJ. Use of a branch wire to anchor stents for exact placement proximal to bifurcation stents: the reverse Szabo technique. Catheter Cardiovasc Interv. 2006;67:904-7.

18. Applegate RJ, Davis JM, Leonard JC. Treatment of ostial lesions using the Szabo technique: a case series. Catheter Cardiovasc Interv. 2008;72:823-8.

19. Gutiérrez-Chico JL, Villanueva-Benito I, Villanueva-Montoto L, VázquezFernández S, Kleinecke C, Gielen S, et al. Szabo technique versus conventional angiographic placement in bifurcations 010-001 of Medina and in aorto-ostial stenting: angiographic and procedural results. Eurolntervention. 2010;5:801-8.

20. Ferenc M, Ayoub M, Büttner H-J, Gick M, Comberg T, Rothe J, et al. Longterm outcomes of routine versus provisional T-stenting for de novo coronary bifurcation lesions: five-year results of the bifurcations Bad Krozingen I study. Eurolntervention. 2015;11:856-9.

21. Tanabe K, Hoye A, Lemos PA, Aoki J, Arampatzis CA, Saia F, et al. Restenosis rates following bifurcation stenting with sirolimus-eluting stents for de novo narrowings. Am J Cardiol. 2004;94:115-8.

22. Colombo A, Stankovic G, Orlic D, Corvaja N, Liistro F, Airoldi F, et al. Modified T-stenting technique with crushing for bifurcation lesions: immediate results and 30-day outcome. Catheter Cardiovasc Interv. 2003;60: $145-51$

23. Chevalier B, Glatt B, Royer T, Guyon P. Placement of coronary stents in bifurcation lesions by the "culotte" technique. Am J Cardiol. 1998:82: 943-9.

24. Behan MW, Holm NR, de Belder AJ, Cockburn J, Erglis A, Curzen NP, et al. Coronary bifurcation lesions treated with simple or complex stenting: 5-year 
survival from patient-level pooled analysis of the Nordic bifurcation study and the British bifurcation coronary study. Eur Heart J. 2016;37:1923-8.

25. Wong P. Two years experience of a simple technique of precise ostial coronary stenting. Catheter Cardiovasc Interv. 2008:72:331-4.

26. Jain RK, Padmanabhan TNC, Chitnis N. Causes of failure with Szabo technique - an analysis of nine cases. Indian Heart J. 2013;65:264-8.

27. Ferrer-Gracia M-C, Sánchez-Rubio J, Calvo-Cebollero I. Stent dislodgement during Szabo technique. Int J Cardiol. 2011;147:e8-9.

\section{Publisher's Note}

Springer Nature remains neutral with regard to jurisdictional claims in published maps and institutional affiliations.

Ready to submit your research? Choose BMC and benefit from:

- fast, convenient online submission

- thorough peer review by experienced researchers in your field

- rapid publication on acceptance

- support for research data, including large and complex data types

- gold Open Access which fosters wider collaboration and increased citations

- maximum visibility for your research: over $100 \mathrm{M}$ website views per year

At $\mathrm{BMC}$, research is always in progress.

Learn more biomedcentral.com/submissions 